Tropical Journal of Pharmaceutical Research December 2017; 16 (12): 2997-3003

ISSN: 1596-5996 (print); 1596-9827 (electronic) (1) Pharmacotherapy Group, Faculty of Pharmacy, University of Benin, Benin City, 300001 Nigeria.

\title{
Determinants of academic stress and stress-related self- medication practice among undergraduate male pharmacy and medical students of a tertiary educational institution in Saudi Arabia
}

\author{
Muhammad Abdullah Al-Shagawi ${ }^{1}$, Rizwan Ahmad ${ }^{2 \star}$, Atta Abbas Naqvi ${ }^{3}$, Niyaz \\ Ahmad $^{4}$ \\ ${ }^{1}$ Department of Pharmacy Practice, ${ }^{2}$ Department of Natural Products and Alternative Medicines, ${ }^{3}$ Department of Pharmacy \\ Practice, ${ }^{4}$ Department of Pharmaceutics, College of Clinical Pharmacy, Imam Abdulrahman Bin Faisal University, Dammam \\ 31441, Saudi Arabia
}

*For correspondence: Email: rizvistar_36@yahoo.com

Sent for review: 18 August 2017

Revised accepted: 20 November 2017

\begin{abstract}
Purpose: To identify factors that promote academic stress and stress-related self-medication practice among undergraduate male students of pharmacy and medical colleges at Imam Abdulrahman Bin Faisal University, Dammam, Saudi Arabia.

Methods: A cross-sectional survey was conducted among undergraduate students of pharmacy and medical colleges of the university. The study used Perceived Stress Scale (PSS) to document academic stress. The responses of the students were analyzed using SPSS version 22.

Results: As many as $51.6 \%$ of students' perceived moderate stress. The majority of students (55.9\%) highlighted examination as a stressor followed by course load (43.2\%) and cGPA (40.4\%). Prevalence of self-medication was 31.58 and $29.20 \%$ among pharmacy and medical students, respectively. Most of the students consumed caffeine (63.8\%) and nicotine (17.8\%) as a drug. Students blamed heavy course load $(23.9 \%)$, followed by assignment load (23\%) and examination (21.1\%) for indulging in self-medication.

Conclusion: Academic stress in undergraduate students in health disciplines is perceived to be high by the students. Examinations, course load and lack of time for leisure are major determinants of stress. Caffeine and nicotine are most frequently used by a majority of the students for self-medication.
\end{abstract}

Keywords: Stress, Self-medication, Stressor, Caffeine, Nicotine, Students

This is an Open Access article that uses a funding model which does not charge readers or their institutions for access and distributed under the terms of the Creative Commons Attribution License (http://creativecommons.org/licenses/by/4.0) and the Budapest Open Access Initiative (http://www.budapestopenaccessinitiative.org/read), which permit unrestricted use, distribution, and reproduction in any medium, provided the original work is properly credited.

Tropical Journal of Pharmaceutical Research is indexed by Science Citation Index (SciSearch), Scopus, International Pharmaceutical Abstract, Chemical Abstracts, Embase, Index Copernicus, EBSCO, African Index Medicus, JournalSeek, Journal Citation Reports/Science Edition, Directory of Open Access Journals (DOAJ), African Journal Online, Bioline International, Open-J-Gate and Pharmacy Abstracts

\section{INTRODUCTION}

Stress may be defined as any non-specific body response towards any change whose outcome may affect one's life. Besides the general populace, students are also victims of stress and its outcomes as reported in various studies [1]. The predisposing factors for stress in students may be lack of sufficient time for managing courses, exams, academic load, social and 
interpersonal issues etc. as supported by a study regarding stress, depression and anxiety conducted in undergraduate students of Kathmandu University Medical School, Nepal. The result of the study revealed a high prevalence for stress $27 \%$, anxiety $41.1 \%$ and depression $29.9 \%$ [1].

Similarly, a study in King Saud Bin Abdulaziz University for Undergraduate Sciences, Riyadh, Saudi Arabia reported $33.8 \%$ of students with severe stress. Nervousness, restlessness, feeling hopeless as well as depression were observed as the predisposing and dominant factors for stress [2].

During preclinical studies and research it has been observed that individuals with stress used to self-medicate hence leading to drug abuse for controlled or addicted substance [3]. The concept of self-medication is widely observed in undergraduate students also as medical students revealed a high ratio i.e. $75.2 \%$ of student with self-medication particularly for analgesics [4] In addition, a study about factors resulting in the use of alcohol and eliciting drugs revealed cannabis as widely used illicit drug among students with stress [5] as well use of nonprescription stimulant medication such as dextroamphetamine and amphetamine, etc [6].

Stress may also affect the sleep patterns of an individual whereby tendency for self-medication of stimulant drugs increases as observed with the use of psychoactive drugs among undergraduate students in a university [7] as well as the use of sedative drugs in undergraduate students at King Saud University, Saudi Arabia. The reasons observed for this stress were low grade point, less sleeping hours per day, poor as well as disturbed sleeping patterns [7].

The aim of this study is to investigate the level of stress and self-medication among undergraduate male students of Imam Abdulrahman Bin Faisal University.

\section{METHODS}

A cross-sectional survey was conducted among undergraduate male students of pharmacy and medicine colleges at Imam Abdulrahman Bin Faisal University (IAU) (formerly University of Dammam) located in the city of Dammam, Saudi Arabia.

\section{Duration and venue of the study}

The study was of four month duration, i.e., February 2017 to May 2017. The venues of the study were College of Clinical Pharmacy and College of Medicine, IAU.

\section{Target population and exclusion criteria}

Male students currently enrolled in these colleges were identified as the target population. Students studying in other universities and dropout students were excluded. Additionally, those who did not consent to participate were also not included.

\section{Research instrument, piloting and validation}

The study used the Perceived Stress Scale (PSS) to document academic stress in target population. The PSS contained 10 - items related to quantifying stress level. It is already validated in Arab population [8]. Hence, there was no need to validate the tool. A separate questionnaire was used to document demographics of students and information about the stressors.

This questionnaire was also developed and validated in the same population. The investigators obtained and used the questionnaire with permission from $\mathrm{Al}$ Rasheed $\mathrm{F}$ [9]. The reliability analysis reported a Cronbach alpha value 0.715 for $\mathrm{N}=10$ items. It was piloted in 29 female students and was validated.

\section{Sampling procedure}

The study used convenient sampling technique. The male students enrolled in pharmacy and medical institutes in Saudi Arabia are 3432 and 9610 [10]. Sum of these two values, i.e., 13042, was the total population used. Sample size was calculated at $95 \%$ confidence level and was 373 [11].

\section{Data analysis}

The responses were entered and analyzed by using SPSS version 22 software. Data were presented in the form of sample counts $(\mathrm{N})$, percentages (\%) and $p$-value. Prevalence data were reported in percentages (\%) and $95 \%$ confidence interval ranges.

\section{Ethical approval and consent}

The students were briefed about the purpose of the study and verbal consent was sought from the respondents before handing them the questionnaire. The study was approved as an undergraduate research project by Department of Pharmacy Practice, College of Clinical Pharmacy. The reference number of approval was 2130000502. 


\section{RESULTS}

\section{Demographics of the respondents}

A total of 213 male students responded to the study. The majority was in age group between 18 to 20 years $(\mathrm{N}=135,63.4 \%)$. The study included students from all academic years i.e. preparatory year to $5^{\text {th }}$ year and from clinical pharmacy $(\mathrm{N}=76,35.7 \%)$ and medicine $(\mathrm{N}=$ $137,64.3 \%$ ) colleges. Almost all students were single $(\mathrm{N}=210,98.6 \%)$ and most of the students stayed with family ( $\mathrm{N}=136,63.8 \%$ ). The majority of students $(\mathrm{N}=161,75.6 \%)$ did not suffer from any disease however, some students reported anxiety ( $\mathrm{N}=21,9.9 \%)$ followed by few students who highlighted obesity $(\mathrm{N}=10,4.7 \%)$ and depression $(\mathrm{N}=8,3.8 \%)$. $\mathrm{A}$ fourth proportion ( $\mathrm{N}=85,39.9 \%$ ) never practiced self-medication. More than half of those students who mentioned practicing selfmedication highlighted the use of caffeine $(\mathrm{N}=$ $136,63.8 \%$ ) followed by some students who consumed nicotine $(\mathrm{N}=38,17.8 \%)$ as a drug. The demographic characteristics are summarized in Table 1 and 2.

Table 1: Respondents' demographic characteristics

\begin{tabular}{lll}
\hline Variable & $\mathbf{N}$ & $\%$ \\
\hline Age (years) & 135 & 63.4 \\
$\mathbf{1 8}$ to 20 & 76 & 35.7 \\
$\mathbf{2 1}$ to 23 & 2 & 0.9 \\
$\mathbf{2 4}$ to 26 & $\mathbf{2 1 3}$ & $\mathbf{1 0 0 . 0}$ \\
Total & & \\
College & 76 & 35.7 \\
Clinical pharmacy & 137 & 64.3 \\
Medicine & $\mathbf{2 1 3}$ & $\mathbf{1 0 0 . 0}$ \\
Total & & \\
Study year & 44 & 20.7 \\
Preparatory year & 78 & 36.6 \\
$\mathbf{2}^{\text {nd }}$ year & 51 & 23.9 \\
$\mathbf{3}^{\text {rd }}$ year & 35 & 16.4 \\
$\mathbf{4}^{\text {th }}$ year & 5 & 2.3 \\
$\mathbf{5}^{\text {th }}$ year & $\mathbf{2 1 3}$ & $\mathbf{1 0 0 . 0}$ \\
Total & & \\
Living status & 77 & 36.2 \\
Campus & & \\
(away from family) & & \\
Stay with family & 136 & 63.8 \\
Total & $\mathbf{2 1 3}$ & $\mathbf{1 0 0 . 0}$ \\
Marital status & & \\
Married & 3 & 1.4 \\
Single & 210 & 98.6 \\
Total & $\mathbf{2 1 3}$ & $\mathbf{1 0 0 . 0}$ \\
\hline
\end{tabular}

\section{Determinants of academic stress}

The majority of the students ( $N=119,55.9 \%)$ higlighted exams followed by those $(\mathrm{N}=92,43.2$ $\%)$ who mentioned course load. Furthermore, nearly half of the students strongly agreed $(\mathrm{N}=$
$86,40.4 \%)$ that cGPA is a stressor for them. Most of the students were unsure whether assignment load ( $\mathrm{N}=82,38.5 \%)$ and competition among classmates $(\mathrm{N}=137,64.3$ $\%)$ are stressors. A third proportion of students $(\mathrm{N}=62,29.1 \%)$ strongly agreed that thinking about career and future perspectives results in academic stress followed by some students $(\mathrm{N}=$ $60,28.2 \%$ ) who mentioned lack of recreational time during semester caused academic stress. Additionally, most of the students $(\mathrm{N}=75,35.2$ $\%$ ) strongly disagreed with the notion of family issues acting as a stressor. The summary of students' response to determinants of academic stress is presented in Table 3 and 4.

Table 2: Respondents' demographic characteristics

\begin{tabular}{lll}
\hline Variable & N & \% \\
\hline Disease information & & \\
Diabetes mellitus & 4 & 1.9 \\
Hypertension & 3 & 1.4 \\
Anxiety & 21 & 9.9 \\
Depression & 8 & 3.8 \\
Obesity & 10 & 4.7 \\
Migraine & 5 & 2.3 \\
Asthma & 1 & 0.5 \\
I do not suffer from any disease & 161 & 75.6 \\
Total & $\mathbf{2 1 3}$ & $\mathbf{1 0 0 . 0}$ \\
Self-medication due to stress & & \\
over the last month & & \\
Always (three day per week) & 13 & 6.1 \\
Often (one day per week) & 21 & 9.9 \\
Sometimes (once in two weeks) & 43 & 20.2 \\
Rarely (once in a month) & 51 & 23.9 \\
Never & 85 & 39.9 \\
Total & $\mathbf{2 1 3}$ & $\mathbf{1 0 0 . 0}$ \\
\hline
\end{tabular}

Prevalence of academic stress among students

A perceived stress scale (PSS) was used to report academic stress among undergraduate students. More than half of respondents $(\mathrm{N}=$ $110,51.6 \%)$ perceived moderate stress. The summary of PSS results is presented in Table 5.

\section{Prevalence of self-medication in stress}

The prevalence of stress related self-medication was documented in two colleges. Comparatively, a high prevalence rate of $31.58 \%$ (21.39 - 43.25 $\%$ for $95 \% \mathrm{Cl}$ ) was observed for pharmacy students followed by prevalence in students of medical college i.e. $29.2 \%(21.75 \%-37.57 \%$ for $95 \% \mathrm{Cl}$ ).

\section{Drug used and reasons for self-medication}

Almost half of the students ( $N=85,39.9 \%)$ never used any drug during stress however, 
most students who indulged in self-medication practice mentioned using caffeine $(\mathrm{N}=136,63.8$ $\%)$ followed by some students ( $\mathrm{N}=38,17.8 \%$ ) who mentioned nicotine. Reasons given as justification for practicing self-mediation by students were: course load ( $\mathrm{N}=51,23.9 \%$ ), examinations, quizzes and assignments ( $\mathrm{N}=49$, $23 \%)$ and examination stress ( $N=45,21.1 \%)$. The summary of results regarding drugs and reasons of self-medication is presented in Table 6.

Table 3: Determinants of academic stress among undergraduate students

\begin{tabular}{lcc}
\hline Determinant & N & $\%$ \\
\hline Stress due to course load & & \\
Strongly agree & 92 & 43.2 \\
Agree & 84 & 39.4 \\
Neutral & 29 & 13.6 \\
Disagree & 5 & 2.3 \\
Strongly Disagree & 3 & 1.4 \\
Total & 213 & 100.0 \\
Stress due to assignment load & & \\
Strongly agree & 35 & 16.4 \\
Agree & 67 & 31.5 \\
Neutral & 82 & 38.5 \\
Disagree & 24 & 11.3 \\
Strongly Disagree & 5 & 2.3 \\
Total & 213 & 100.0 \\
Stress due to exams & & \\
Strongly agree & 119 & 55.9 \\
Agree & 67 & 31.5 \\
Neutral & 21 & 9.9 \\
Disagree & 4 & 1.9 \\
Strongly Disagree & 2 & 0.9 \\
Total & 213 & 100.0 \\
Stress due to competition among classmates \\
Strongly agree & 33 & 15.5 \\
Agree & 35 & 16.4 \\
Neutral & 77 & 36.2 \\
Disagree & 43 & 20.2 \\
Strongly Disagree & 25 & 11.7 \\
Total & 213 & 100.0 \\
\hline
\end{tabular}

Cross tabulation of demographic variables and perceived stress score

The cross tabulation between college and perceived stress score (PSS) was significant ( $p$ value < 0.05). Similarly, living status of students was also significantly assciated with stress score ( $p$ value < 0.05). The variables such as age group, college and study year were not statistically significant. The summary of cross tabulations is presented in Table 7 and 8.

\section{DISCUSSION}

Academic stress has become a psychological challenge for students that need to be tackled as it has the potential to cause emotional and mental breakdown which may hinder academic performance and growth. This study was conducted in male students of pharmacy and medicine colleges who were studying in different academic years. The students were mostly single in age group 18 to 20 years and lived with their family [12]. Two thirds of respondents highlighted good self-perceived health and well-being. This was in concordance with earlier findings and was a characteristic feature of Saudi academia $[9,13-$ 15].

Academic stress was reported using Perceived Stress Scale (PSS). We found that almost half of the students perceived moderate stress followed by a third segment who perceived high academic stress. This figure was similar to the stress reported among female students by Al Rasheed et al [9], however, it was dissimilar to the findings in British students where percentage of students

Table 4: Determinants of academic stress among undergraduate students

\begin{tabular}{lcc}
\hline Determinants & $\mathbf{N}$ & $\%$ \\
\hline Stress due to thinking about career & and & future \\
perspectives & \multicolumn{2}{c}{} \\
Strongly agree & 62 & 29.1 \\
Agree & 79 & 37.1 \\
Neutral & 52 & 24.4 \\
Disagree & 13 & 6.1 \\
Strongly Disagree & 6 & 2.8 \\
Total & 213 & 100.0 \\
Stress due to lack of recreational time (free time) \\
during semester & \multicolumn{2}{c}{} \\
Strongly agree & 60 & 28.2 \\
Agree & 62 & 29.1 \\
Neutral & 61 & 28.6 \\
Disagree & 25 & 11.7 \\
Strongly Disagree & 5 & 2.3 \\
Total & 213 & 100.0 \\
Stress due to cGPA & \multicolumn{2}{c}{} \\
Strongly agree & 86 & 40.4 \\
Agree & 74 & 34.7 \\
Neutral & 37 & 17.4 \\
Disagree & 9 & 4.2 \\
Strongly Disagree & 7 & 3.3 \\
Total & 213 & 100.0 \\
Stress due to family issue & & \\
Strongly agree & 16 & 7.5 \\
Agree & 30 & 14.1 \\
Neutral & 46 & 21.6 \\
Disagree & 46 & 21.6 \\
Strongly Disagree & 75 & 35.2 \\
Total & 213 & 100.0 \\
\hline
\end{tabular}

Table 5: Perceived stress score interpretation

\begin{tabular}{lcc}
\hline $\begin{array}{l}\text { Perceived Stress Score } \\
\text { Interpretation }\end{array}$ & $\begin{array}{c}\text { Sample } \\
\text { (N) }\end{array}$ & $\%$ \\
\hline Low perceived stress (Less than 13) & 40 & 18.8 \\
Moderate perceived stress (13 to 20) & 110 & 51.6 \\
High perceived stress (Above 20) & 63 & 29.6 \\
Total & $\mathbf{2 1 3}$ & $\mathbf{1 0 0 . 0}$ \\
\hline
\end{tabular}


Table 6: Drugs used and reasons for self-medication

\begin{tabular}{lcc}
\hline Variable & $\mathbf{N}$ & $\%$ \\
\hline Drugs used for self-medication & 38 & 17.8 \\
Nicotine (Smoking) & 136 & 63.8 \\
Caffeine (Coffee/Tea) & 5 & 2.3 \\
Amphetamine (Methylphenidate) & 20 & 9.4 \\
Mood enhancers (Escitalopram, Fluoxetine) & 1 & 0.5 \\
Memory Enhancers (Ginseng, Ginkgo) & 1 & 0.5 \\
Personal Issues (Viagra, Yohimbine etc.) & 12 & 5.6 \\
Antihistaminic drugs (Cetirizine, loratadine etc.) & 213 & 100.0 \\
Total & & 5.6 \\
Reasons for self medication & 12 & 0.9 \\
Lack of sleep & 2 & 23.9 \\
Family problems & 51 & 21.1 \\
Course load & 45 & 0.5 \\
Examination stress & 1 & 0.9 \\
Hospital rounds & 2 & 0.5 \\
Lack of Proper Environment at University & 1 & 1.4 \\
Lack of Proper environment at Hostels & 3 & 0.5 \\
No free time for recreational activities & 1 & 0.5 \\
No free time for gatherings & 1 & 2.8 \\
Financial Problems & 6 & 6.6 \\
Personal Issues & 14 & 23.0 \\
Health Issues & 49 & 11.7 \\
Exams, quizzes and assignments & 25 & $\mathbf{1 0 0 . 0}$ \\
Course load and no free time for gathering and recreational activities & $\mathbf{2 1 3}$ & \\
\hline
\end{tabular}

Table 7: Cross tabulation between study variables and perceived stress score $(N=213)$

\begin{tabular}{|c|c|c|c|c|c|}
\hline \multicolumn{2}{|c|}{ Cross-tabulation } & \multicolumn{3}{|c|}{ Observed (expected) } & \multirow[t]{2}{*}{$\begin{array}{c}P \text { - } \\
\text { value }\end{array}$} \\
\hline \multirow[b]{2}{*}{$\begin{array}{l}\text { Age group } \\
\text { (years) }\end{array}$} & & Perc & stress score & & \\
\hline & $\begin{array}{l}18 \text { to } 20 \\
21 \text { to } 23 \\
24 \text { to } 26\end{array}$ & $\begin{array}{c}\text { Low } \\
(<13) \\
22(25.4) \\
18(14.3) \\
0(0.4)\end{array}$ & $\begin{array}{c}\text { Moderate } \\
\text { (13 to 20) } \\
71(69.7) \\
39(39.2) \\
0(1)\end{array}$ & $\begin{array}{c}\text { High } \\
\text { (Above 20) } \\
42(39.9) \\
19(22.5) \\
2(0.6)\end{array}$ & $>0.05$ \\
\hline \multirow{4}{*}{ College } & \multicolumn{4}{|c|}{ Perceived stress score } & \multirow{4}{*}{0.02} \\
\hline & & $\begin{array}{l}\text { Low perceived } \\
\text { stress (<13) }\end{array}$ & $\begin{array}{c}\text { Moderate } \\
\text { perceived stress } \\
(13 \text { to 20) }\end{array}$ & $\begin{array}{l}\text { High perceived } \\
\text { stress }(>20)\end{array}$ & \\
\hline & $\begin{array}{l}\text { Clinical } \\
\text { pharmacy }\end{array}$ & $17(14.3)$ & $45(39.2)$ & $14(22.5)$ & \\
\hline & Medicine & $23(25.7)$ & $65(70.8)$ & $49(40.5)$ & \\
\hline
\end{tabular}

Table 8: Cross tabulation between study variables and perceived stress score

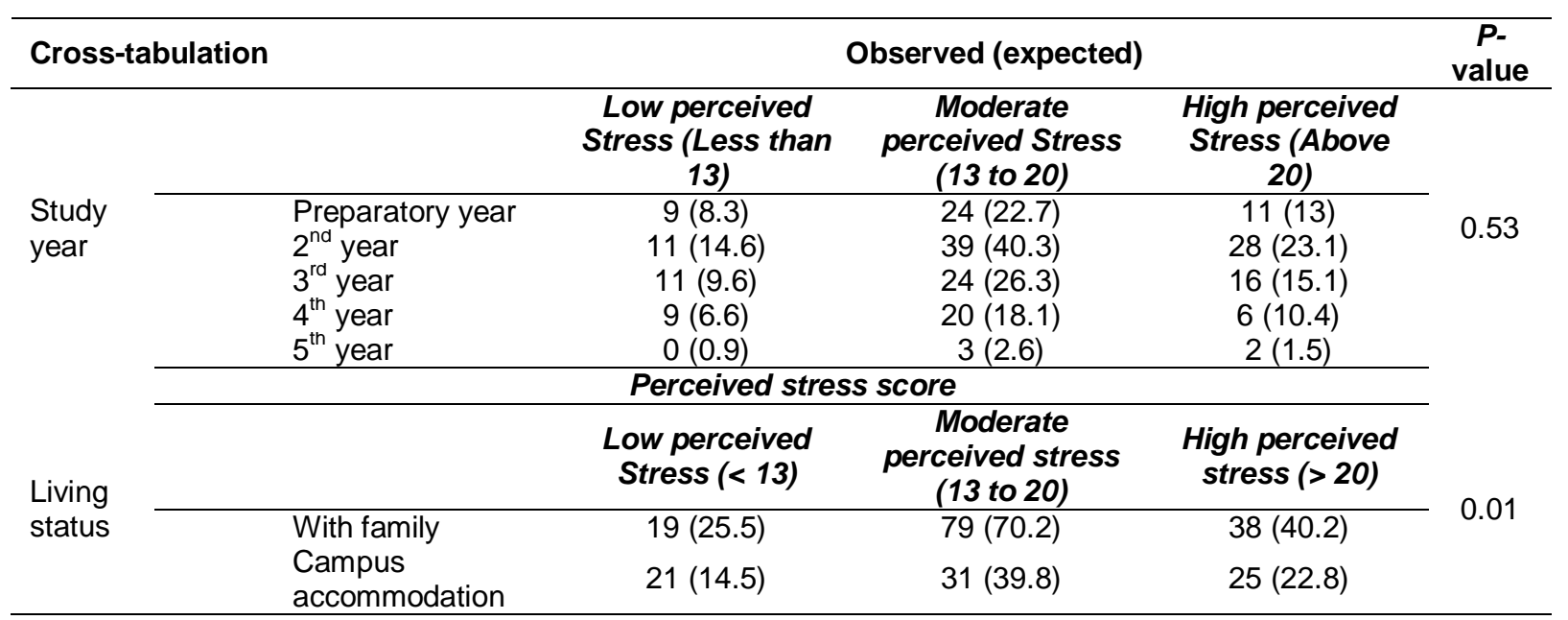


who perceived high stress was much lower [16]. This finding denotes that Saudi students perceive moderate to high academic stress [17,2]. Our study reported no association of some demographic variables such as age groups, study year, college affiliations and living status with PSS score. This entails that academic stress is prevalent in this population regardless of age, study year, college and residential status. This finding is contradictory to previous literature and is a novel finding in this academic environment.

Most of the students mentioned examination, course load and cumulative grade point average cGPA as stressors (in descending order). This is in accordance with the results of the study of $\mathrm{Al}$ Rasheed et al among female students studying at the same venue which also reported examination and course load as stressors [9]. Further to this, students studying in other universities of Saudi Arabia highlighted same factors that promote academic stress among them $[2,3,9]$. Hence, examination and course load may be considered as general determinants of stress among Saudi students.

Exam preparation may result in prolonged study duration and may encompass days and night times hence requiring CNS stimulants such as caffeine. We observed that students who indulged in self-medication mostly consumed caffeine followed by some who self-medicated with nicotine. The prevalence of self-medication in stress among students of Medicine and Pharmacy colleges was reported at $29.20 \%$ and $31.58 \%$. Those who mentioned consuming caffeine used it in the form of tea, coffee and energy drinks. In this context, it was important to describe the extent to which caffeine was not considered as a drug. Students were asked to clarify if their dietary pattern changed with respect to consuming tea, coffee and energy drink in stress and if it was consumed in larger amount than standard intake. A study conducted among high school students in Riyadh city reported a nominal consumption of caffeine in the form of energy drinks (5\%) during exams. This finding implied that consumption of caffeine has increased a lot among higher secondary students during examination period which is one of the stressor [18].

Additionally, nicotine was the second most common drug highlighted by students. Study conducted among female students at the same venue reported absolutely no consumption of nicotine which draw attention to that fact that it was mainly used by male students as a recreational drug that may not relate to any stressor [9]. An interesting observation in our study was use of amphetamines i.e. methylphenidate. Though in less but significant numbers, students mentioned using methylphenidate during stress. This encores the findings of Baker who observed that Saudi Arabia witnessed an increase in the use of such drugs [19]. Further to this, the use of CNS stimulants among households in Saudi Arabia was reported at $16 \%$ a decade ago [20]. In this context, a study conducted among pharmacy students of Karachi, Pakistan reported a prevalence of psychoactive stimulants use of around $8 \%$ [21]. The encouraging point that can be considered from this finding is the percentage of students who mentioned using methylphenidate was a minute $2.3 \%$.

\section{Limitations of the study}

This was a cross-sectional study and collected responses from the students at a single point in time. The timeline of the data collection included examination period and semester classes that may result in measurement bias. However, the authors excluded the examination time period and timed the data collection in off-peak days to overcome measurement bias.

\section{CONCLUSION}

The study documents the academic stress and stress-related self-medication practice among pharmacy and medical students. We found that the prevalence of self-medication in stress is higher among pharmacy students than medical students. Stress among the students is moderate to high, and is mainly due to examinations and heavy course load. Consumption of caffeine dramatically increases during examination periods among the students.

\section{DECLARATIONS}

\section{Conflict of interest}

The authors declare that no conflict of interest exists with regard to this study.

\section{Contribution of authors}

We declare that this work was done by the authors named in this article and all liabilities pertaining to claims relating to the content of this article will be borne by the authors. MAS and RA executed the idea, presented a research proposal and collected the data. AAN and NA helped data entry into SPSS file. RA and AAN performed statistical analysis. MAS and RA wrote and produced a final shape of the 
manuscript. AAN and NA wrote the result and discussion as well review of article for expert opinion and any grammatical or language errors.

\section{REFERENCES}

1. Kunwar D, Risal A, Koirala S. Study of Depression, Anxiety and Stress among the Medical Students in two Medical Colleges of Nepal. Kathmandu Univ Med $J$ 2016; 14(53): 22-26.

2. Saeed AA, Bahnassy AA, Al-hamdan NA, Almudhaibery FS, Alyahya AZ. Perceived stress and associated factors among medical students. J Family Community Med 2016; 23(3): 166-171.

3. Aashi MM, Alghanmi $H A$, Alhibshi $R H$, Alsaati $B A$, Aljohani NJ. Self-medication among medical student in King Abdul-Aziz University. Int J Res Med Sci 2016; 4(3): 942-946.

4. Newbury-birch $D$, White $M$, Kamali F. Factors influencing alcohol and illicit drug use amongst medical students. Drug Alcohol Depend 2000; 59(2): 125-130.

5. Al-sayed AA, Al-rashoudi AH, Al-eisa AA. Sedative Drug Use among King Saud University Medical Students: A Cross-Sectional Sampling Study. Depress Res Treat 2014, Article ID 378738. http://dx.doi.org/10.1155/ 2014/378738

6. Mcniel AD, Muzzin KB, Dewald JP. The nonmedical use of prescription stimulants among dental and dental hygiene students. J Dent Educ 2011; 75(3): 365-376.

7. Lund $H G$, Reider $B D$, Whiting $A B$, Prichard JR. Sleep patterns and predictors of disturbed sleep in a large population of college students. $J$ Adolesc Undergraduate 2010; 46(2): 124-132.

8. Almadi T, Cathers I, Hamdan Mansour AM, Chow CM. An Arabic version of the perceived stress scale: translation and validation study. Int J Nurs Stud 2012; 49(1): 84-89.

9. Al-Rasheed F, Naqvi AA, Ahmad R, Ahmad N, Al Ghamdi MS. Academic stress and prevalence of stress related self-medication among undergraduate female students of health and non-health cluster colleges of a public sector university in Dammam, Saudi Arabia. (Unpublished).

10. Health Statistics Annual Book. Ministry of Health. Kingdom of Saudi Arabia; 2014-15. Available at http://www.moh.gov.sa/en/ministry/statistics/book/docu ments/1433.pdf. Accessed 27 April 2017.

11. Sample size calculator. The Survey System. Available online: https://www.surveysystem.com/sscalc.htm.

12. Ahmad R, Naqvi AA, Ahmad N, Baraka M, Mastour M, AlSharedah S, Al-Ghamdi S, Al-Rabae G. Awareness, Perception, Attitude, and Knowledge Regarding Complementary and Alternative Medicines (CAMs) Among the Pharmacy and Medical Students of a Public University in Saudi Arabia. Arch Pharma Pract 2017; 8: 51-63.

13. Albusalih FA, Naqvi AA, Ahmad R, Ahmad N. Prevalence of self-medication among students of pharmacy and medicine colleges of a public sector university in Dammam City, Saudi Arabia. Pharmacy 2017; 5: 51.

14. Abdel-Rahman AG, Al-Hashim BN, Al-Hiji NK, Al-abbad Z. Stress among medical Saudi students at College of Medicine, King Faisal University. J Prev Med Hyg 2013; 54: 195-199.

15. Taha AZ, Sabra AA. Perceived stresses among male students in University of Dammam, Eastern Saudi Arabia: a comparative study. J Ameri Sci 2012; 8(6): 291-298.

16. Aboserie R. Sources and Levels of Stress in Relation to Locus of Control and Self Esteem in University Students. Edu Psych 1994; 14(3): 323-330.

17. Saipanish $R$. Stress among medical students in a Thai medical school. Medical Teacher 2003; 25(3): 502-506.

18. Almalak H, Al-bluwi AA, Al-khelb DA, Al-saleh HM, Khan TM. Students' attitude toward use of over the counter medicines during exams in Saudi Arabia. Saudi Pharmaceut J 2014; 22(2): 107-112.

19. Baker A. Conservative Saudi Arabia Is Becoming a Hotbed for Amphetamines. Time. Available online: http://world.time.com/2013/10/29/conservative-saudiarabia-is-becoming-a-hotbed-for-amphetamines/.

20. Abou-Auda HS. An economic assessment of the extent of medication use and wastage among families in Saudi Arabia and Arabian Gulf countries. Clin Ther 2003; 25(4): 1276-1292.

21. Abbas A, Ahmed FR, Yousuf R, Khan N, Nisa ZN, Ali SI, Rizvi M, Sabah A, Tanwir S. Prevalence of SelfMedication of Psychoactive Stimulants and Antidepressants among Undergraduate Pharmacy Students in Twelve Pakistani Cities. Trop J Pharm Res 2015; 14(3): 527. 